\title{
ENSAIOS
}

\section{O RIO DA PESQUISA}

\author{
THE RESEARCH'S RIVER
}

\begin{abstract}
Allan Hoffmann ${ }^{1}$
Resumo: A experiência da pesquisa é um caminho único e rico de aprendizagem. Neste texto, o rio revela pela sua latente possibilidade de metáfora a perspectiva de um(a) pesquisador(a) nas tramas da pesquisa. Entre o rio e um(a) pesquisador(a), no encontro de sensibilidades, a coexistência e o vínculo propiciam numa escrita íntima compreender o entrelaçamento da ciência na vida pessoal, de um rio em seus meandros.
\end{abstract}

Palavras-chave: Pesquisa; rio; meandro.

\begin{abstract}
The research experience is a unique and rich way of learning. In this text, the river reveals by its latent possibility of metaphor the perspective of a researcher in the plots of the research. Between the river and a researcher, in the encounter of sensibilities, the coexistence and bonding allow in an intimate writing to understand the intertwining of science in personal life, of a river in its meanders.
\end{abstract}

Keywords: Research; river; meandre.

\author{
O rio que fazia uma volta atrás de nossa casa \\ era a imagem de um vidro mole que fazia uma \\ volta atrás de nossa casa. \\ Passou um homem e disse: Essa volta \\ que o rio faz por trás de sua casa se chama \\ enseada. \\ Não era mais a imagem de uma cobra de vidro \\ que fazia uma volta atrás de casa. \\ Era uma enseada. \\ Acho que o nome empobreceu a imagem. \\ Manoel de Barros
}

Quantas são as possíveis poéticas retratáveis de um rio? Existe alguma que não poderia servir de metáfora à vida? Bem, sei que no meu quintal nunca atravessou nenhum rio. Em toda minha infância poucos rios me marcaram pois, estive sempre perto do mar. Eu achava que o mar, dada a sua infinitude, seria fonte inesgotável de toda poesia do mundo. Mas foi no rio que encontrei infinitas formas de me fazer compreendido, já que sempre há uma latente metáfora a ser desvelada. Aliás, foi entre as metáforas de Rubens Alves que redescobri a beleza da leitura/escrita. O texto metafórico alcança exatamente onde minha compreensão e imaginação permitem. Nunca é demais, nem de menos. Para mim, uma metáfora pouco ou nada explicada, é a evidência de humildade de quem escreve em abordar assuntos acompanhando os ritmos de entendimento de cada um.

Concluída minha dissertação de mestrado ${ }^{2}$, senti uma enorme necessidade de mostrar pelo rio e sua perspectiva, a descrição de um processo de escrita e a experiência da pesquisa. Não tenho

\footnotetext{
${ }^{1}$ Universidade da Região de Joinville, Joinville, SC, Brasil.

${ }^{2}$ Dissertação apresentada em 2019, intitulada como "Corpo e Memória: os fenômenos na Trilha da Vida".
} 
dúvidas de que o processo, o meio do caminho, importa a muitos, muito mais do que os princípios e fins de qualquer caminhada. Sempre irei me encantar ao compreender as características de um rio que se encontra com o mar, observando a dinâmica e o fluxo de seu escoamento. Pois sei que nesta dinâmica, é onde o rio se transforma, onde se faz realmente mudado por sua trajetória, estudos, leituras, ou seja, por toda a pesquisa. Desta forma, desejo desdobrar-me a partir do que um rio ensina sobre minha experiência de pesquisa, revelando a potência da informação do processo.

De modo muito simples, um rio inicia sempre em sua montante, o lugar inicial de encontro das águas, das nascentes. Neste ponto, a inclinação do solo é maior do que na jusante, onde se encaminha para a foz, o encontro com o mar. Mais próximo a sua jusante, normalmente um rio adquire a característica peculiar de meandrar, de fazer curvas, devido à baixa inclinação do terreno. Lembro de uma frase que percorre uma extensa parede em uma exposição fixa do Museu Oscar Niemeyer em Curitiba/PR, do próprio arquiteto: "se a reta é o caminho mais curto entre dois pontos, a curva é o que faz o concreto buscar o infinito". Talvez o meandro seja a vontade do rio de não terminar, nem se diluir em oceano. Os meandros então, são os processos ou os caminhos de um rio da montante para a jusante. Um recorte de extensão de terra saboreada.

Entre estes dois pontos, os meandros podem assumir inúmeras conformidades. Ora serpenteiam com maior intensidade aproveitando a potência de seu fluxo e o interesse da descoberta, ora preferem o caminho mais curto quando o devaneio acontece ou o desafio desinteressa. A disponibilidade do rio para seu caminho, é ao mesmo tempo, uma atitude de respeito e desrespeito ao esqueleto de sua narrativa. Concordo com Moser quando escreve que é preciso ser "distraído e alerta no mundo" (MOSER, 1992, p. 224). É possibilitar no trajeto, que o descontrole assuma primazia no papel do percurso, uma vez que a indeterminação permite seu enriquecimento. $\mathrm{O}$ descontrole do rio permite atender um fluxo intuitivo que, a princípio, poderia não ser tido como essencial. Desta forma, os meandros aparecem pela própria interrogação do rio com o terreno, esclarecendo suas dúvidas e necessidades. E sempre são, ou pelo menos deveriam ser, coerentes com a existência do próprio rio.

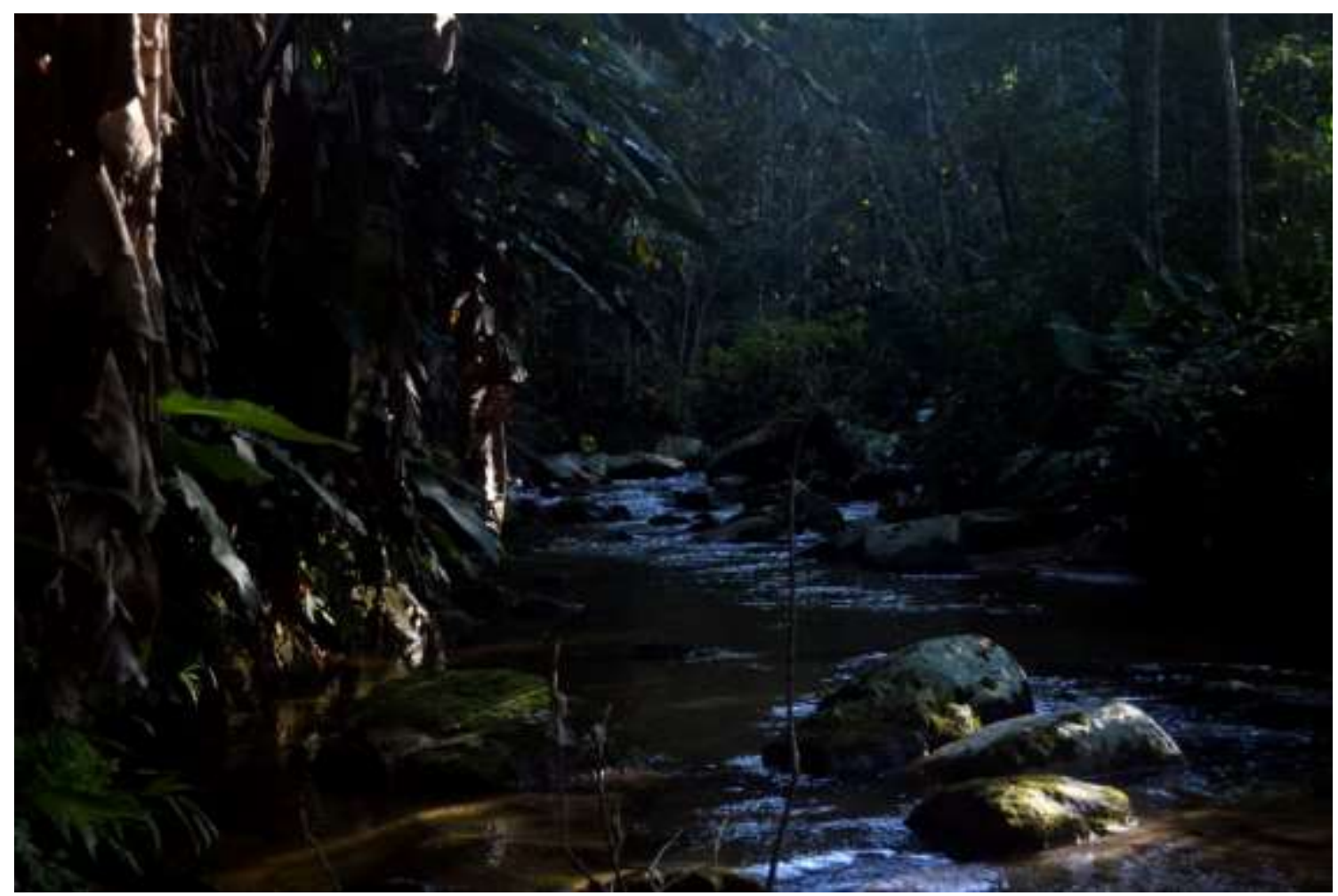

Figura 1 - Uma das inúmeras perspectivas do rio - Fotografia do autor, 2019 
Tive a imensa oportunidade de realizar minha pesquisa no mesmo território onde descobri formas e meios de libertação às durezas da ciência. Esses territórios foram primordiais para a garantia de fôlego no itinerário acadêmico. Contudo, contrapondo a nomeação descontrolada às coisas da ciência, este rio da fotografia para mim nunca teve nome. Não tive que conhecê-lo assim, formalmente. Foi vivendo e precisando deste, que sua presença atendeu à minha existência. Toda vez que chego neste território, numa área rural de Camboriú/SC, priorizo contemplar o rio antes de qualquer coisa, porque sei que nos dias atuais fazemos do tempo, este subjetivo, um convite permanente à aceleração. Assim, no início do dia da observação dos fenômenos na pesquisa, fui para o fim do terreno encontrá-lo, na tentativa de fincar no tempo minha atenta presença a vida, visto que segundo Matarezi "tempo é vida que deve ser vivida e experienciada com todos os sentidos" (MATAREZI, 2017, p. 80). Passados alguns minutos, a ansiedade da pesquisa já tinha se misturado com o conforto da segurança de se estar em um território conhecido, uma espécie de pertencimento deflagrado pelo vínculo com o rio. Sei que tive o privilégio de uma coparticipação especial na pesquisa.

Mesmo que um rio serpenteie com toda intensidade e sua extensão aumente em centenas de vezes tendendo ao infinito, ele sempre é atraído por sua jusante. Assim, entre o início e o fim, mesmo buscando seu infinito, um rio não pode alcança-lo devido aos tempos/espaços do processo, mas pode compor com clareza num fluir desestruturado, improvisos inesperados e compassos assertivos.

Quando não meandram, não se abandonam ao prazer da descoberta de um novo solo, um novo território, uma nova eureka. Por vezes, a foz alarma o prazo de sua chegada, e assim, faz o rio se adiantar e o meandro encurtar. Ou, as histórias deste rio e suas enformações, só permitem que o meandro se amplie e, se estenda até onde possa alcançar. O importante é que o rio se reconheça em sua vazão, que inclusive é única, para compreender até onde pode ou não meandrar evitando processos de poluição e adoecimento tornando o autocuidado, fonte principal de vida. Quero deixar claro que rio saudável é o que meandra. Fico ressentido pelos rios que não meandram, retificados pelo padrão, segurança ou pela tecnicidade humana que estreita inúmeras possibilidades de descoberta. O racionalismo humano tende retificar qualquer sensibilidade eminente. Nestas ocasiões, os desejos e as vontades individuais do rio são raramente atendidos.

Maffesoli (1998) comenta que quando o racionalismo surgiu, logo traçou suas incapacidades de compreensão da vida. Muitos assuntos, num largo processo histórico não foram legitimados como autobiografias, sensibilidades, intuições e poesias. Por isso, faço a pergunta de Rubens Alves (1999) as minhas: o que é científico, ou mesmo, o que veem como científico? Talvez em um contexto político tão abalado, o científico voltou a ser retificado ressurgindo velhas dúvidas. O mensurável, a progressão intelectual analítica e ultratecnicidade fazem que o fluxo de água chegue mais rápido ao mar. Às vezes, imagino que a repreensão criativa do meandro seja tão grande que o rio não possa mais se conectar com seus desejos e sua habilidade inerente de meandrar. Talvez nem mais se reconheça como rio.

É preciso que escoe muita água. Quando o fluxo se apresenta com muita intensidade, o meandro se arredonda com tanto vigor que, estreita-se um atalho formando um meandro abandonado. Esses abandonos são os anseios do rio, deixados a princípio de lado para que possam ser revisitados em outras narrativas. Enfim, este texto nada mais é do que, um meandro abandonado. Um desejo de descrição para voltar a ver no meandro, a curva do corpo da imensa cobra de vidro. 


\section{Referências}

ALVES, Rubens. Entre a ciência e a sapiência: o dilema da educação. São Paulo: Edições Loyola, 1999.

BARROS, Manoel. O livro das ignorãças. Rio de Janeiro: Civilização Brasileira, 1994.

MAFFESOLI, Michel. Elogio da razão sensível. Petrópolis: Vozes, 1998.

MATAREZI, José. "Trilha Da Vida" - Labirintos que se entretecem nos campos da Educação Ambiental e Patrimonial. 2017. Dissertação (Mestrado em Patrimônio Cultural e Sociedade) Universidade da Região de Joinville, Joinville, 2017.

MOSER, Alvino. O método fenomenológico nas ciências sociais. Veritas: revista da Pontifícia Universidade Católica do Rio Grande do Sul, v. 37, n. 146, p. 215-224, 1992.

\section{Sobre o autor}

Allan Hoffmann. Graduado em Oceanografia (Universidade do Vale do Itajaí), tem Mestrado em Patrimônio Cultural e Sociedade (Universidade da Região de Joinville). É pesquisador participante do GEARCUPA (Grupo de Estudo sobre Arte Cultura e Patrimônio) da Universidade da Região de Joinville, e pesquisador colaborador da abordagem teórica metodológica "Trilha da Vida: (Re)Descobrindo a Natureza com os Sentidos" do Laboratório de Educação Ambiental da Universidade do Vale do Itajaí. Tem experiência no campo da Educação Ambiental, e pesquisas interdisciplinares em Arte\&Ciência, Educação, Patrimônio e Ciências Ambientais.

E-mail: allan_0101@hotmail.com. 